\title{
BIOCHEMICALLY ACTIVE SUBSTANCES FROM ACTINOMYCETES AND OTHER ORGANISMS. II
}

\author{
EFFECTS OF VARIOUS COMPOUNDS ON MOTILOMETRY
}

\author{
Haruyoshi Azuma and Hiromi B. Maruyama \\ Department of Microbiology and Chemotherapy \\ Nippon Roche Research Center \\ 200 Kajiwara, Kamakura-247, Japan
}

(Received for publication November 29, 1973)

\begin{abstract}
Effects of various compounds known to affect the bacterial or protozoan motility on the motility of Escherichia coli S-26 were examined by a newly-devised simple method, motilometry. Under catabolite repression, adenosine $3^{\prime}, 5^{\prime}$-cyclic phosphate as well as theophylline was found to stimulate the motility in this system. On the other hand, some alkaloids like eseline, strychnine and atropine, membrane-active compounds such as phenethyl alcohol and levallorphane, respiration inhibitors or several metals showed a strong inhibition at a concentration causing no or little growth inhibition.
\end{abstract}

In the previous paper $^{11}$, we established a simple and quantitative assay method for the motility of Escherichia coli in a thin glass tube in an attempt to screen for motility inhibitors or stimulators from cultured broth of actinomycetes and other microorganisms. In this method, E. coli Strain S-26 inoculated at the top of a tube filled with motility medium were allowed to migrate towards the tip and the motility was quantified by the distance from the inoculated position to the spearhead of migration.

The present paper reports the effects of various compounds known to affect the motility of various organisms and adenosine- $3^{\prime}, 5^{\prime}$-cyclic phosphate metabolism on the motility of $E$. coli S-26. The new assay system, motilometry, was examined in order to obtain a perspective on possible usability of this method for screening.

\section{Material and Methods}

Bacterial Strain and Cultural Conditions

Escherichia coli strain S-26 ${ }^{1 l}$ was used throughout the experiment. Cultural conditions used for preculture and the migration culture in the motility medium (MM) were the same as described in the previous paper ${ }^{11}$. Repression medium (GMM) contained $0.04 \mathrm{~m}$ glucose.

Motility Measurement

Test compounds were mixed with hot MM and packed in a sterilized glass tube as described previously ${ }^{1 \prime}$. Incubation was done under standard conditions in a vertical position ${ }^{11}$. The distance of migration in $\mathrm{mm}$ from the inoculated position to the two bands observed in some cases (Bands I, II) or the spearhead point of turbid area was determined. The percent inhibition or stimulation was calculated from the distances of migration with test compounds and the control.

\section{Chemicals}

Adenosine-3', $5^{\prime}$-cyclic monophosphate (cAMP) was purchased from Daiichi Chem., Tokyo. Penicillin $G$ and chloramphenicol were generous gifts from Dr. T. TAKeuchi, Institute of Microbial Chemistry, and from Sankyo Co., respectively. Levallorphane (1, 3-hydroxy-N-allyl- 
morphinane) tartarate was a product of F. Hoffmann-La Roche AG. Basle. Other chemicals used were purchased mostly from Wako Chem. Co., Ltd., Tokyo.

\section{Results and Discussion}

\section{Repression of Motility by the Addition of Various Sugars}

The presence of $0.01 \sim 0.1 \mathrm{M}$ glucose inhibited the motility of strain S-26 depending upon the concentration. Glucose-containing media caused the formation of characteristic bands (I and II) around the spearhead of the migration ${ }^{11}$. Table 1 shows the effect of other sugars or related compounds on the motility by the present method. As is clearly seen, sugars such as galactose, maltose, lactose and deoxyribose or sodium lactate and pyruvate caused a similar inhibition of the motility, while sucrose, ribose and glycerol showed no effect. It was noted that, in most cases, the reduction in motility corresponded to the increase in growth rate, suggesting a close relation of motility to the utilization of sugars and hence the motility inhibition of the catabolite repression type. This fact is generally consistent with the finding of Buettrer et $a l .^{2)}$ on the relationship between catabolite repression and cAMP

Table 1. Effect of sugar on motility and growth of E. coli S-26

\begin{tabular}{|c|c|c|c|c|}
\hline \multirow{2}{*}{ Sugar } & \multirow{2}{*}{$\underset{(\mathrm{M})}{\text { Conc. }}$} & \multicolumn{2}{|c|}{ Relative motility $(\%)$} & \multirow{2}{*}{$\begin{array}{c}\text { Growth } \\
\text { doubling } \\
\text { time* (min.) }\end{array}$} \\
\hline & & Band II & Band I & \\
\hline $\begin{array}{c}\text { Non sugar-MM } \\
\text { (control) }\end{array}$ & & —** & 100.0 & 61 \\
\hline Glucose & 0.05 & $56.2 * *$ & $80.0 * * *$ & 43 \\
\hline Galactose & 0.05 & $(59)^{+}$ & 78.9 & 44 \\
\hline Fructose & 0.05 & 64.5 & 94.6 & 52 \\
\hline Deoxyribose & 0.05 & - & 41.7 & 60 \\
\hline Ribose & 0.05 & - & 104.3 & 54 \\
\hline Glycerol & 0.05 & - & 101.8 & 49 \\
\hline Na-Pyruvate & 0.05 & 66.2 & 92.1 & 49 \\
\hline Na-Lactate & 0.05 & + & 92.5 & 50 \\
\hline Sucrose & 0.05 & - & 95.3 & 64 \\
\hline Maltose & 0.05 & + & 82.8 & 47 \\
\hline Lactose & 0.05 & $(70)^{+}$ & 95.0 & 48 \\
\hline
\end{tabular}

* Doubling time was obtained from a shaking culture in MM minus agar by the use of a MONOZ type tube, followed by turbidity.

** Band II was not formed.

*** Relative motility: percent of the migrated distance to that in MM (Band I of control=100\%).

+ The formation of Band II was not quite reproducible. where carbon sources that rather poorly supported growth gave higher intracellular concentration of cAMP than did sugars that supported rapid growth.

Also noticeable is that Band II was not formed in the presence of sucrose, maltose, ribose, deoxyribose, glycerol and lactate. The reason for this phenomenon remain to be clarified as well as the inhibition by various sugars.

\section{Effect of Vitamins and Amino Acids on the Motility}

The effects of vitamins and amino acids on the migration of Bands I and II in GMM are summarized in Table 2. It is shown that none of those listed gave any significant inhibition or stimulation on motility in this method, when added to GMM at a concentration of $1 \mathrm{mM}$. It is known that some amino acids like serine and asparagine are potent chemotactic attractant of $E . \operatorname{coli}^{3)}$ in a synthetic semi-solid medium. However, in the present system, since the motility was examined in a rich medium such as GMM containing various amino acids originated 
from casein and yeast

Table 2. Effect of vitamins and amino acids (L-) on relative motility extract, it is quite reasonable that an extra-supplmentation of amino acid causes no positive effect on the motility. This fact in turn provides an advantage in that any motility stimulator selected by this method would not be active by virtue of chemotactic events mediated by chemotactic receptor sites

\begin{tabular}{l|c|c|l|r|r}
\hline \multirow{2}{*}{$\begin{array}{c}\text { Compound } \\
(1 \mathrm{~mm})\end{array}$} & \multicolumn{2}{|c|}{$\%$ Migration } & \multicolumn{2}{|c|}{$\begin{array}{c}\text { Compound } \\
(1 \mathrm{~mm})\end{array}$} & \multicolumn{2}{c}{$\%$ Migration } \\
\cline { 2 - 3 } & Band I & Band II & & Band I & Band II \\
\hline Control & 100 & 100 & Cysteine & 98.3 & 96.7 \\
Glycine & 97.0 & 95.2 & Methionine & 95.8 & 92.4 \\
Alanine & 96.2 & 94.3 & Phenylalanine & 97.9 & 95.2 \\
Valine & 98.3 & 97.6 & Tyrosine & 94.9 & 92.9 \\
Leucine & 94.1 & 91.9 & Tryptophane & 91.5 & 93.9 \\
Isoleucine & 99.2 & 97.6 & Thiamine-HCl & 99.6 & 100.0 \\
Serine & 84.7 & 91.0 & Roboflavin & 105.9 & 105.0 \\
Threonine & 81.7 & 89.2 & Pyridoxine-HCl & 98.1 & 98.3 \\
Aspartic acid & 93.6 & 93.3 & Ascorbic acid & 99.6 & 99.5 \\
Glutamic acid & 96.2 & 95.2 & Nicotinic acid & 100.0 & 102.1 \\
Proline & 102.5 & 100.5 & Biotin & 101.5 & 101.3 \\
Arginine & 97.0 & 97.1 & Calcium-D- & 98.1 & 99.2 \\
Histidine & 91.5 & 90.5 & pantothenate & & \\
Lysine & 98.7 & 93.8 & & & \\
\hline
\end{tabular}
for amino acids ${ }^{4}$.

3. Effect of Various Compounds Known to Affect the Motility in Other Systems on the Motility Observed in the Present System

Table 3 demonstrates the effect of various compounds on the motility in this system. It was found that such alkaloids as atropine and strychnine showed a strong inhibition $(40 \sim 50 \%)$ at $10^{-3} \mathrm{M}$. The inhibitory effect of colchicine known to depolymerize the microtubule structure $\mathrm{e}^{51}$ was not marked in comparison with the others mentioned above. It should be noted that the inhibition percent on Bands I and II was significantly different from each other in some cases, and that, in cases where a srong inhibition was found on Band I, no formation of Band II was in general observed. Table 3-a shows that membrane-affecting compounds such as levallorphane and phenethyl alcohol were found to strongly inhibit the motility. The primary point of action of these compounds is known to be damage of the plasma membrane which causes permeability changes, instability of the surface and changes in phospholipid composition that, all together, eventually result in inhibition of nucleic acid synthesis, breakdown of ATP and so forth ${ }^{6,7)}$. Since the minimal inhibition concentration (MIC) of levallorphane on growth of S-26 was found to be $2 \mathrm{mg} / \mathrm{ml}$ by the broth dilution method, the $50 \%$ inhibition concentration of motility $(110 \mu \mathrm{g} / \mathrm{ml})$ was approximately one twentieth of the MIC and roughly equivalent to the concentration causing spheroplast lysis of $E$. coli strain $\mathrm{K} 12$ as reported by Fromageot et al ${ }^{81}$. Similarly, phenethyl alcohol caused motility inhibition at a concentration far lower than the lethal dose. As can be seen, some detergents and antibiotics attacking the cell surface also inhibited motility in this system (Table 3, a and c). However, even such antibiotics like chloramphenicol and tetracycline that are known to inhibit protein synthesis also showed a strong motility inhibition at a concentration far less than their MIC values (Table 3-c). This fact may suggest the involvement of some specific protein synthesis in cell movement as assayed by the present system. It also indicates the possible use of the motilometry as a sensitive assay method 
for certain types of antibiotics.

That all respiration inhibitors tested uninformly showed a strong inhibition at a concentration causing little growth inhibition (Table 3-b) indicated a close relationship between the energy generating system and motility. Similar effects of these compounds were observed with Pseudomonas fluorescens by FAUST and Doetsch ${ }^{9 !}$. Since no ATPase activity was found in bacterial flagellar filaments ${ }^{10)}$, the energy for flagellar movement may be directly or indirectly mediated by the membrane where the respiratory chain and oxidative phosphorylation systems are thought to be arranged. Regarding the mechanism of the movement, there are few reports relating to the concrete events. According to a speculation of VAIRUzis and Doetsch, membraneous locomotion was considered to give the force for the movement ${ }^{111}$. From the present

(a)

Table 3. Effect of various compounds on the relative motility and growth

\begin{tabular}{|c|c|c|c|c|}
\hline \multirow{2}{*}{ Compound added } & \multirow{2}{*}{ Conc. (M) } & \multicolumn{2}{|c|}{$\%$ Migration } & \multirow{2}{*}{$\begin{array}{l}\text { Growth-doubling } \\
\text { time (min.) }\end{array}$} \\
\hline & & Band II & Band I & \\
\hline Control (GMM only) & & 100 & 100 & 48 \\
\hline Acetylcholine & $10^{-3}$ & 69.6 & 80.3 & 48 \\
\hline Sodium barbital & $10^{-3}$ & 69.6 & 63.7 & 48 \\
\hline Atropine sulfate & $10^{-3}$ & 60.1 & 54.0 & 48 \\
\hline Eseline sulfate & $10^{-3}$ & 60.1 & 53.3 & 48 \\
\hline Strychnine sulfate & $10^{-3}$ & - & 47.8 & 48 \\
\hline Colchicine & $10^{-3}$ & 95.5 & 85.3 & 48 \\
\hline$\beta$-Phenethyl alcohol & $10^{-3}$ & 36.5 & 40.0 & 48 \\
\hline Levallorphane & $10^{-3}$ & - & 20.0 & ND* \\
\hline Triton X-100 & $1 \mathrm{mg} / \mathrm{ml}$ & 76.3 & 74.1 & 48 \\
\hline Sodium dodecylsulfate & $5 \times 10^{-4}$ & - & 12.5 & 48 \\
\hline Cacodylic acid & $10^{-3}$ & 96.6 & 73.7 & 48 \\
\hline Sodium fluoride & $10^{-3}$ & 97.8 & 97.0 & 48 \\
\hline EDTA & $5 \times 10^{-4}$ & - & 4.3 & ND* \\
\hline Lysozyme & $20 \mu \mathrm{g} / \mathrm{ml}$ & 99.5 & 99.3 & ND \\
\hline
\end{tabular}

(b)

\begin{tabular}{|c|c|c|c|c|c|}
\hline \multirow{2}{*}{ Compound added } & \multicolumn{2}{|c|}{ Motility inhibition } & \multirow{2}{*}{ M.I.C.*** } & \multirow{2}{*}{$\frac{\mathrm{ID}_{50}}{\text { M.I.C. }} \times 100(\%)$} & \multirow{2}{*}{$\frac{\mathrm{ID}_{90}}{\text { M.I.C. }} \times 100(\%)$} \\
\hline & $\mathrm{ID}_{50} * *$ & $\mathrm{ID}_{90} * *$ & & & \\
\hline Potassium cyanide & $0.20 \mathrm{~mm}$ & $1.00 \mathrm{~mm}$ & $8.0 \mathrm{~mm}$ & $2.5 \%$ & $12.5 \%$ \\
\hline Dinitrophenol & 0.05 & 0.10 & 2.0 & 2.5 & 5.0 \\
\hline Sodium azide & 0.015 & 0.40 & 3.0 & 5.0 & 13.3 \\
\hline
\end{tabular}

\begin{tabular}{|c|c|c|c|c|c|}
\hline \multicolumn{6}{|l|}{ (c) } \\
\hline Chloramphenicol & $0.70 \mu \mathrm{g} / \mathrm{ml}$ & $1.0 \mu \mathrm{g} / \mathrm{ml}$ & $5.0 \mu \mathrm{g} / \mathrm{ml}$ & $14.0 \%$ & $20.0 \%$ \\
\hline Tetracycline & 0.22 & 0.40 & 5.0 & 4.4 & 8.8 \\
\hline Penicillin G & 7.0 & 12.0 & 50.0 & 14.0 & 24.0 \\
\hline Novobiocin & 20.0 & 40.0 & 200 & 10.0 & 20.0 \\
\hline Polymyxin B & 0.22 & 0.80 & 2.0 & 11.0 & 40.0 \\
\hline
\end{tabular}

* ND: not determined.

** $\mathrm{ID}_{50}$ and $\mathrm{ID}_{90}$; the concentration exhibiting $50 \%$ and $90 \%$ inhibition of motility.

*** MIC, the minimal inhibition concentration of growth determined by agar-dilution method. 
results, specific inhibition of energy generation may be speculated to bring about a strong inhibition of motility.

Effects of the addition of metals on the motility are shown in Table 4. A strong inhibition was found in cases with $10^{-3} \mathrm{M}$ concentration of $\mathrm{Cu}^{2+}, \mathrm{Hg}^{2+}$, $\mathrm{Co}^{2+}$, and $\mathrm{Ag}^{+}$.

\section{Reversal of the Motility} Inhibition by cAMP

Cyclic AMP reversed the repression in motility caused by glucose or other sugars in this system, confirming the results reported previously by other $\operatorname{methods}^{12,13)}$. Fig. 1-a demonstrates that a migration greater than in MM was observed in the GMM to which more than 1 mм cAMP was added. In the range from 0.1 to $3 \mathrm{~mm}$, the migration distance of Band I increased as a function of cAMP concentration. On the other hand, the repression of motility by lactose was reversed only to the non-repression value (Fig. 1-b) although the reversal appeared at lower concentrations of cAMP $(0.01 \sim 0.05 \mathrm{~mm})$ than those in GMM. When the reversed distance (migration in MM minus that in sugar-containing $\mathrm{MM}$ ) is double-reciprocally plotted as the function of cAMP, a linear relationship is seen as

Table 4. Effect of metal on bacterial motility

\begin{tabular}{|c|c|c|c|c|}
\hline \multirow{2}{*}{ Compounds } & \multirow{2}{*}{$\begin{array}{c}\text { Conc. } \\
\text { (M) }\end{array}$} & \multicolumn{2}{|c|}{$\%$ Migration } & \multirow{2}{*}{$\begin{array}{l}\text { Growth } \\
\text { doubling time } \\
\text { (min.) }\end{array}$} \\
\hline & & Band II & Band I & \\
\hline Control & & 100 & 100 & 40.5 \\
\hline $\mathrm{CuCl}_{2}$ & $10^{-4}$ & -* & 7.5 & 41 \\
\hline \multirow[t]{2}{*}{$\mathrm{AgNO}_{3}$} & $10^{-4}$ & - & 0.4 & No growth \\
\hline & $2 \times 10^{-5}$ & 57.9 & 63.3 & 41 \\
\hline \multirow[t]{2}{*}{$\mathrm{HgCl}_{2}$} & $10^{-5}$ & - & 4.2 & No growth \\
\hline & $5 \times 10^{-6}$ & - & 12.4 & 41 \\
\hline $\mathrm{CoCl}_{2}$ & $5 \times 10^{-4}$ & 43.8 & 57.4 & 115.5 \\
\hline $\mathrm{KCrO}_{4}$ & $5 \times 10^{-4}$ & - & 50.7 & 42 \\
\hline $\mathrm{ZnSO}_{4}$ & $10^{-3}$ & 60.5 & 69.8 & 40 \\
\hline $\mathrm{PbCl}_{2}$ & $10^{-3}$ & 69.9 & 52.5 & 41.0 \\
\hline $\mathrm{BaCl}_{2}$ & $10^{-3}$ & - & 42.3 & 121.5 \\
\hline $\mathrm{CaCl}_{2}$ & $10^{-3}$ & 70.1 & 78.1 & _** \\
\hline $\mathrm{MgSO}_{4}$ & $10^{-3}$ & 80.2 & 89.4 & - \\
\hline $\mathrm{LiCl}$ & $10^{-3}$ & 94.6 & 93.6 & - \\
\hline $\mathrm{FeSO}_{4}$ & $10^{-3}$ & 95.8 & 97.0 & - \\
\hline $\mathrm{FeCl}_{3}$ & $10^{-3}$ & 97.0 & 94.7 & - \\
\hline $\mathrm{MnCl}_{2}$ & $10^{-3}$ & 112.6 & 102.3 & - \\
\hline$\left(\mathrm{NH}_{4}\right)_{6} \mathrm{Mo}_{7} \mathrm{O}_{24}$ & $10^{-3}$ & 92.8 & 94.7 & - \\
\hline $\mathrm{NaCl}$ & $10^{-2}$ & 98.4 & 96.4 & - \\
\hline $\mathrm{NH}_{4} \mathrm{Cl}$ & $10^{-2}$ & 102.8 & 102.1 & - \\
\hline
\end{tabular}

* Not observed. ** Not determined.

Fig. 1. Reversal of the repressed motility by cAMP. The migration distance of Bands I and II are plotted as the function of cAMP concentration integrated in MM containing $50 \mathrm{mM}$ of glucose (a) or lactose (b).

(a)

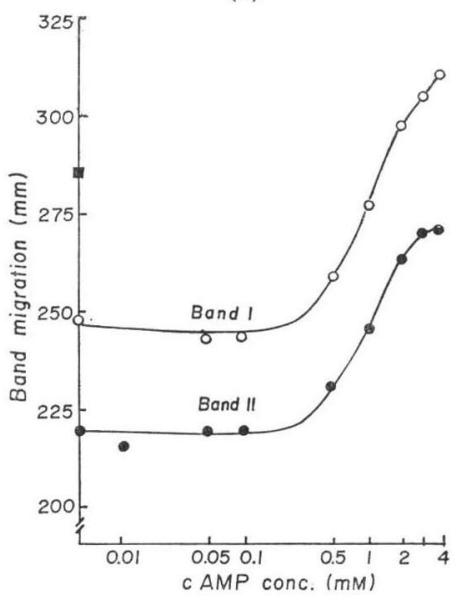

(b)

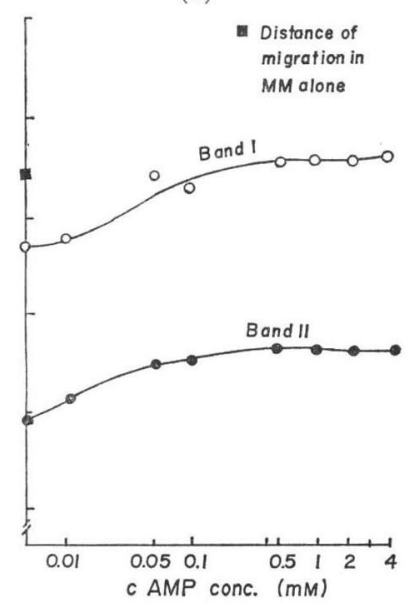
shown in Fig. 3. The apparent $\mathrm{Km}$ of cAMP was between $1.6 \sim 2.5 \times 10^{-3} \mathrm{M}$ for glucose, deoxyribose and maltose but was smaller for galactose $\left(4 \times 10^{-4} \mathrm{M}\right)$.

The effects of theophylline and sodium fluoride were examined in this connection. Both 
Fig. 2. Double reciprocal plot of the recovered distance (normalized) with respect to cAMP. Vo is the normalized distance in the presence of $50 \mathrm{~mm}$ sugar.
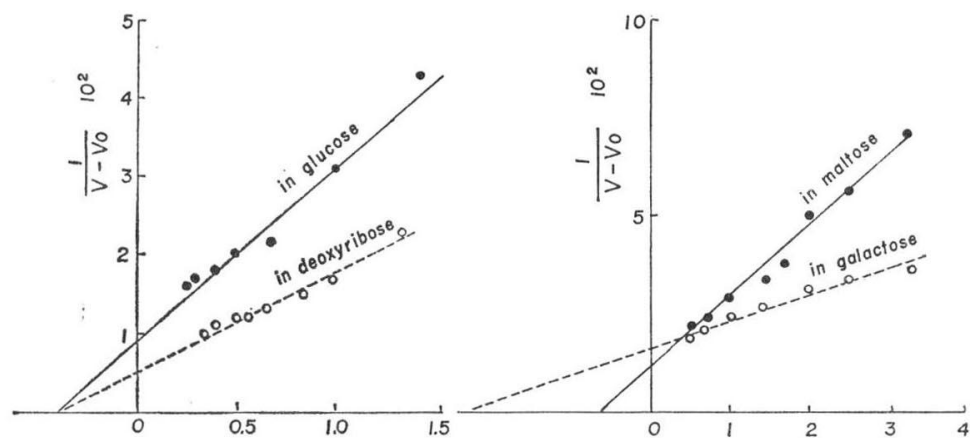

$\frac{1}{\operatorname{cAMP}(\mathrm{mM})}$

are known to elevate cAMP level in the animal system either by inhibition of cAMP phosphodiesterase ${ }^{14}$ or by activation of adenyl cyclase ${ }^{15 !}$. Fig. 3 shows that theophylline has a marked reversing effect on repressed motility at concentrations less than $5 \mathrm{~mm}$. However, a strong inhibition of motility is seen at higher concentrations. On the other hand, sodium fluoride gave no significant reversing effect (Table 3-a), which is consistent with the fact that it does not activate bacterial adenyl cyclase ${ }^{16)}$. Although the precise mechanism of theophylline action remains to be clarified, it is conceivable that theophylline elevates the endogeneous cAMP level by inhibiting the degrading enzyme ${ }^{151}$.

Fig. 4 shows the reversing effect of cAMP on the motility inhibition caused by various compounds. It is clear that there are three distinct types of reversal pattern. The reversal of atropine inhibition represents Type $I$ in which the motility inhibited by atropine did not recover by increasing addition of CAMP. Strychnine, tetracycline and SDS were found to belong to this type. Type II is the case where the inhibition was completely reversed by the addition of a sufficient concentration of cAMP: colchicine, phenethyl alcohol, dinitrophenol and cyanide showed this type of reversal. Type III consists of the pattern in which the reversal was obtained at a certain concentration of cAMP but, at a higher concentration of cAMP, it was inhibitory. This type was seen with sodium azide and penicillin G. No explanation can be given at present for this phenomenon, although the difference in the type of pattern may be associ-
Fig. 3. Effect of theophylline on the motility. The migration percent of Bands $I$ and II in GMM (no addition in $\mathrm{GMM}=100 \%$ ).

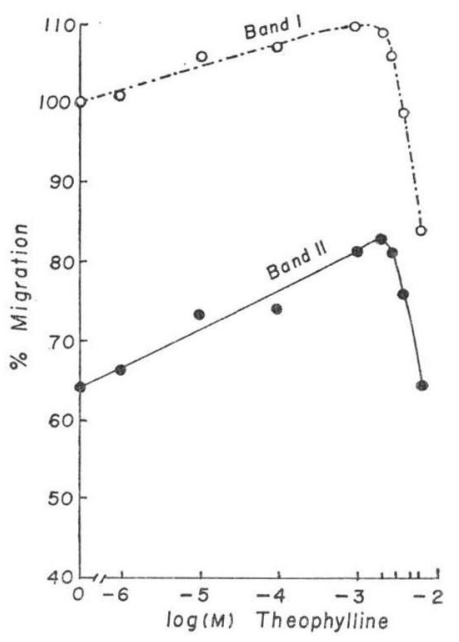

Fig. 4. Differential reversal by cAMP of the motility inhibition caused by various compounds. Percent migration at 0 concentration of $\mathrm{CAMP}$ is $30 \%, 63 \%$ and $30 \%$ to the no-addition control for $5 \mathrm{~mm}$ atropine, $10 \mathrm{~mm}$ colchicine and $0.1 \mathrm{~mm} \mathrm{NaN}_{3}$, respectively.

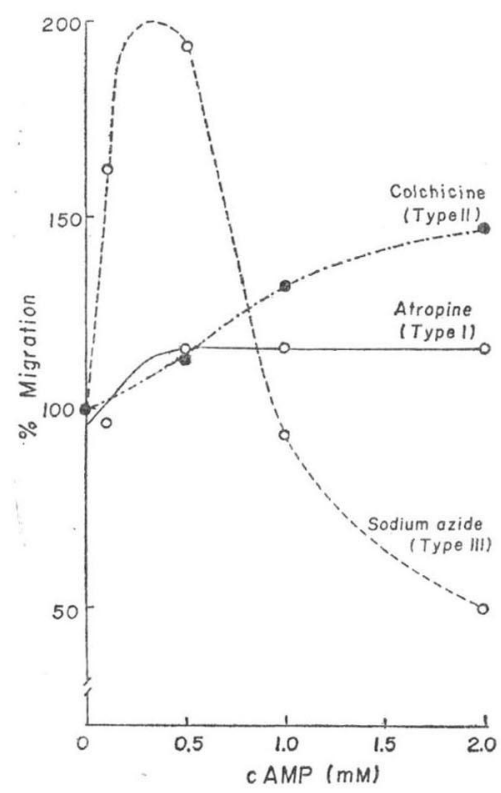


ated with their different mechanism of inhibition.

\section{Usability of the Motilometry for Screening}

The effect of various compounds known to inhibit motility of various organisms by various methods were compared by this method. The results obtained showed that most of such compounds as neurotransmittance blockers, respiration inhibitors, microtubule depolymerizers and membrane-active substances and some metals exhibited inhibitory activity in the present system at a concentration causing no growth inhibition of $E$. coli. Chemotactic activity of certain amino acids was eliminated in this system by the presence of various amino acids present in casein and yeast extracts. The assay method, motilometry, is considered to be interesting as a simple screening system for compounds of the types discussed above, provided that the presence of heavy metals are taken into the consideration. Characterization of a unique substance obtained from the culture broth of a Streptomyces by this method will be reported in the subsequent paper $^{17)}$.

\section{References}

1. Maruyama, H. B. \& H. Azuma: Biochemically active substances from actinomycetes and other organisms. I. "Motilometry", a simple and quantitative assay method for motility inhibitors. J. Antibiotics 27: 178 184, 1974

2. Buettner, M. J.; E. Spitz \& H. V. Rickenberg: Cyclic adenosine 3', 5'-monophosphate in Escherichia coli. J. Bact. 115: 1068 1073, 1973

3. Mesibov, R. \& J. Adlen: Chemotaxis toward amino acids in Escherichia coli. J. Bact. 112: 315 326,1972

4. Adler, J.: Chemoreceptors in bacteria. Science 166: 1588 1591, 1969

5. Ehrlich, M.P. \& P. Bornstein: Effect of microtubule function on procollagen/collagen conversion rate. Nature, New Biol. 238: 257 260, 1972

6. Boquet, P. L.; M. A. Deuvnck \& P. Fromageot: Involvement of RC locus in RNA synthesis inhibition by levallorphane in Escherichia coli. FEBS Letters 13: 279 281, 1971

7. Wenclt, L. W. \& N. Walls: Inhibition of bacterial motility by membrane-altering drugs. Bacteriol. Proc. 1968: p. 29, 1968

8. Boquet, P. L.; M. A. Deunnck, H. Aurelle \& P. Fromageot: On the bactericidal action of levallorphane: Irreversible alterations of the plasmic membrane. Eur. J. Biochem. 21: 536 541, 1971

9. Faust, M. A. \& R. N. Doetsch: Effect of respiratory inhibitors on the motility of Pseudomonas fluorescens. J. Bact. 97: 806 811, 1969

10. Depharpilis, M. L. \& J. Adler: Attachment of flagellar basal bodies to the cell envelope: Specific attachment to the outer, lipopolysaccharide membrane and the cytoplasmic membrane. J. Bact. 105: $396 \sim 407,1971$

11. Vaituzis, Z. \& R. N. Doetsch: Relationship between cell wall, cytoplasmic membrane, and the bacterial motility. J. Bact. 100: 512 521, 1969

12. Yокота, T. \& J.S. Gots: Requirement of adenosine $3^{\prime}, 5^{\prime}$-cyclic phosphate for flagella formation in Escherichia coli and Salmonella typhimurium. J. Bact. 103: 513 516, 1970

13. Dobrogosz, W. J. \& P. B. Hamilton: The role of cyclic AMP in chemotaxis in Escherichia coli. Biochem. Biophys. Res. Commun. 42: 202 207, 1971

14. Butcher, R. W. \& E. W. Sutherland: Adenosine-3', 5'-phosphate in biological materials. I. Purification and properties of cyclic $3^{\prime}, 5^{\prime}$-nucleotide phospho-diesterase and use of this enzyme to characterize adenosine 3', 5'-phosphate in human urine. J. Biol. Chem. 237: 1244 1250, 1964

15. Birnbaumer, L.; S. L. Pohl \& M. Rodbell: Adenyl cyclase in fat cells. I. Properties and the effects of adrenocorticotropin and fluoride. J. Biol. Chem. 244: 3468 3476, 1969

16. IDE, M.: Adenyl cyclase of bacteria. Arch. Biochem. Biophys. 144: 262 268, 1971

17. Azuma, H.; Y. Котoh, Y. Suhara \& H. B. Maruyama: Biochemically active substances from actinomycetes and other organisms. III. Motility inhibitor Ro 09-0067, which reverses the activity of cyclic AMP. Abst. 94th Ann. Meeting of Jap. Soc. Pharm. Sci., 1974; manuscript in preparation. 